\title{
Technical Note: A Near-Infrared Reflectance Spectroscopy Technique to Predict Particle Size of Starch Within Corn Silage
}

\author{
A. Zwald, ${ }^{\star}$ A. E. Dorshorst, ${ }^{\star}$ P. C. Hoffman, ${ }^{* 1}$ L. M. Bauman, $\dagger$ and M. G. Bertram‡ \\ *Department of Dairy Science, \\ †Department of Soil Science, and \\ $\ddagger$ Agricultural Research Stations, University of Wisconsin, Madison 53706
}

\section{ABSTRACT}

Starch particle size characteristics of 81 diverse corn silage samples, which included 27 combinations of hybrid, planting dates, and harvest dates subjected to 3 different degrees of kernel processing, were determined via vertical shaking through 9 screens with nominal square apertures of 19.0, 13.2, 9.5, 6.7, 4.75, 3.35, 2.36, 1.18 , and $0.6 \mathrm{~mm}$ and a pan. Starch content of dry matter remaining on each screen and on the pan for each corn silage was determined, and geometric mean particle size (GMPS, $\mu \mathrm{m}$ ), starch particles(SP)/g, starch surface area (SSA, $\left.\mathrm{cm}^{2} / \mathrm{g}\right)$, kernel processing score (KPS), \% starch $<4.75 \mathrm{~mm}$, and the percentage of total starch remaining on each screen of the vertical shakers were calculated. Near-infrared reflectance spectra were obtained by scanning 3 types of samples: $1 \mathrm{~mm}$ of dried ground corn silage; whole undried, unground corn silage; and undried, unground corn silage that passed through a 19-mm screen. Calibrations to predict GMPS, SP, SSA, and KPS characteristics of corn silage starch were attempted from each spectral origin. Calibrations to predict GMPS, SP, SSA, KPS, and the percentage of total starch retained on screens of the vertical shaker was unattainable $\left(R^{2}<0.45\right)$ using spectra obtained from $1 \mathrm{~mm}$ of dried ground corn silage or whole undried, unground corn silage. However, reasonable near-infrared reflectance spectra equations $\left(\mathrm{R}^{2}>0.81\right)$ for GMPS, SSA, and KPS were attained using spectra from undried, unground corn silage that passed through a 19$\mathrm{mm}$ screen. This technique holds promise as a rapid and efficient method to determine particle size characteristics of starch within corn silage.

Key words: near-infrared reflectance spectra, corn silage, particle size, starch

Kernel processing of corn silage at harvest increases starch digestion (Bal et al., 2000) and lactation perfor-

Received November 5, 2007.

Accepted January 3, 2008.

${ }^{1}$ Corresponding author: pchoffma@facstaff.wisc.edu mance of dairy cows (Cooke and Bernard, 2005). Quantifying the geometric mean particle size (GMPS) of starch in corn silage with or without kernel processing in commercial forage testing systems has been challenging. Vertical shaking separation procedures have been used routinely to evaluate particle size of starch (Ferreira and Mertens, 2005) in corn silage, but DM retained on screens of a vertical shaker contains both forage and starch (grain) particles. Therefore, subsequent determination of the starch content of the DM remaining on each screen ( 7 to 14 screens) and in the pan to partition starch particles (SP) from forage particles is required. As a commercially viable surrogate, Ferreira and Mertens (2005) recommended determining the starch content of the total sample and the starch content of the DM remaining on screens $>4.75 \mathrm{~mm}$ for corn silage. This yields a kernel processing score (KPS) that serves as a SP size index for corn silage.

Near-infrared reflectance spectrophotometers (NIRS) fit with a natural product cell can predict particle size of industrial materials (Pasikatan et al., 2001) as well as ingredient composition of heterogeneous feeds (Pérez-Marin et al., 2004). Direct prediction of GMPS of starch in undried, unground corn silage using natural product cell NIRS technique would be a highly efficient method for determining GMPS of starch in corn silage, because samples would not have to be dried, ground, vertically shaken or separated. The objective of this experiment was to determine whether NIRS could be used to predict the particle size characteristics of starch within corn silage.

A sample set of corn silages was compiled to evaluate the experimental objective. Three varieties of corn that differed in relative maturity $(110,93,74 \mathrm{~d})$ were each planted on April 26, May 18, and June 5 at Marshfield, Wisconsin $\left(44^{\circ} 39^{\prime} \mathrm{N} 90^{\circ} 08^{\prime} \mathrm{W}\right)$ and were chopped at 1.9 $\mathrm{cm}$ theoretical length of cut on September 6, 20, and October 4. Fresh corn silage samples were ensiled directly or following 2 degrees of kernel processing. For processing, small ( 3 to $4 \mathrm{~kg}$ ) samples of corn silage were processed through a stationary roller mill (A.O. Smith Harvestore, Dekalb, IL) set at a roller clearance of ei- 
ther 1 or $3 \mathrm{~mm}$. Immediately after harvest or after kernel processing, approximately $1.5 \mathrm{~kg}$ of fresh corn silage was placed in a plastic bag, vacuum-sealed, and allowed to ferment for $150 \mathrm{~d}$. In total, 81 corn silage samples consisting of the 3 hybrids at 3 planting and 3 harvesting dates subjected to the 3 processing methods were conserved. After fermentation, the silage bags were opened, and DM (AOAC, 1990) and total starch content (Ehrman, 1996) were determined. For determination of GMPS, SP per gram, starch surface area (SSA), and KPS of the starch in each silage sample, $200 \mathrm{~g}$ was dried for $48 \mathrm{~h}$ at $55^{\circ} \mathrm{C}$ in a forced-air oven. These dried corn silage samples were placed in a vertical shaker (W.S. Tyler Incorporated, Mentor, OH) fitted with 9 screens with nominal square apertures measuring $19.0,13.2,9.5,6.7,4.75,3.35,2.36,1.18$, and 0.6 $\mathrm{mm}$ and a pan and shaken for $20 \mathrm{~min}$. After shaking, DM remaining on each screen was weighed and ground through an Udy mill (Udy Corp., Boulder, Co.) fitted with a 1-mm screen. Residual DM was determined by drying for $3 \mathrm{~h}$ in a $105^{\circ} \mathrm{C}$ oven. Starch content of the DM remaining on each vertical shaker screen for each corn silage $(n=891)$ was determined by NIRS using a Foss 6500 (Foss North America Inc., Eden Prairie, MN) at the University of Wisconsin Soil and Forage Testing Laboratory, Marshfield. The NIRS equation used to determine the starch content of DM remaining on each vertical shaker screen had an $\mathrm{R}^{2}$ of 0.97 with a $\mathrm{SE}$ of calibration of $0.045 \mathrm{~g} / \mathrm{kg}$. The GMPS, SP, and SSA of starch for each corn silage were calculated as described by ASAE (1993) as modified by Baker and Herrman (2002) using the grams of starch remaining on each screen and the nominal dimension of the square aperture instead of the diagonal dimension. The KPS of each corn silage was calculated as described by Ferreira and Mertens (2005) as the percentage of total SP that pass through a $4.75-\mathrm{mm}$ screen. Finally, starch as a percentage of total starch retained on each vertical shaker screen also was calculated.

To evaluate the utility of NIRS to predict particle size characteristics of starch in corn silage, 3 sets of NIRS spectra were obtained and saved. First, any differences in GMPS of starch in corn silages were purposely mitigated by drying and grinding a subsample of each corn silage through a 1-mm screen (Udy Corp.). These ground samples were packed into a quarter cup rectangular transport cell equipped with a quartz window and scanned with a Foss 5000 NIRS (Foss North America Inc.) between 1,100 to 2,498 nm according to the procedures of Marten et al. (1983). Spectra were saved and served as negative control. These negative control spectra, in which SP size characteristics in corn silage were mitigated (1-mm grind), were used to evalu- ate whether any chemical artifacts in corn silage were related to SP size.

A second set of NIRS spectra was obtained and saved from unground, undried corn silage samples scanned on a Foss 5000 NIRS fitted with a natural product cell. Each undried, unground corn silage was thoroughly mixed, and approximately $50 \mathrm{~g}$ of whole corn silage was packed into a natural product cell (Foss North America Inc.) and scanned from 1,100 to 2,498 nm. A third set of NIRS spectra was obtained and saved by identical methods as the second set with one exception. In this case, the whole undried, unground corn silage was separated before scanning by shaking the whole undried, unground corn silage through the top screen of a Penn State Forage Particle Separator using the methods of Lammers et al. (1996). This separator has a nominal round aperture of $19.0 \mathrm{~mm}$ and a thickness of $12.2 \mathrm{~mm}$. A 50-g subsample of undried, unground corn silage that passed through the $19-\mathrm{mm}$ screen was packed into the natural product cell and scanned. Separation before scanning was an attempt to partially standardize total particle size (forage and grain) of corn silage and to recover and concentrate the SP in the natural product cell before scanning. Fractional corn silage retained on the 19-mm screen of the Penn State Particle Separator does not typically contain whole corn kernels (Lammers et al., 1996). We realized that long forage particles and cobs retained on a $19-\mathrm{mm}$ screen could contain some fine particles of starch that might influence the capability of NIRS to properly predict SP size characteristics of the corn silage.

Calibrations for total starch, GMPS, SP, SSA, KPS, and starch as a percentage of total starch retained on each screen of the vertical shaker were computed using partial least squares regression methods, exploring a matrix of 27 math treatments with a maximum of 8 terms allowed to avoid overfitting. Calibration performance was evaluated using cross validation (Shenk and Westerhaus, 1991), where the prediction error is evaluated by dividing calibration sample spectra into subsets $(\mathrm{n}=6)$ with 1 subset reserved for validation and the remaining subsets used for calibration. Cross validation was repeated until all subsets were used for validation once. Strength of calibration performance was based on the cross-validation coefficient of determination, the standard error of cross validation corrected for bias, and the mean bias.

Summary statistics of nutrients and particle size characteristics of starch in the corn silages are presented in Table 1. Tested corn silages were diverse with $\mathrm{DM}$ and starch ranging from 22.5 to $48.6 \%$ and 10.8 to $45.6 \%$, respectively. Likewise, the GMPS of starch in corn silages ranged from 1,836 to $5,619 \mu \mathrm{m}$ with robust differences in KPS and starch retained on different 
Table 1. Summary statistics of nutrients and particle size of starch in database corn silages

\begin{tabular}{|c|c|c|c|c|}
\hline \multirow[b]{2}{*}{ Item } & \multicolumn{4}{|c|}{$\mathrm{n}=81$} \\
\hline & Mean & $\mathrm{SD}$ & Minimum & Maximum \\
\hline \multicolumn{5}{|l|}{ Nutrient } \\
\hline $\mathrm{DM}, \%$ & 35.4 & 6.2 & 22.5 & 48.6 \\
\hline Starch, \% of DM & 31.5 & 7.0 & 10.8 & 45.6 \\
\hline \multicolumn{5}{|c|}{ Starch retained (screen size), $\%$ of starch } \\
\hline $19.0 \mathrm{~mm}$ & 0.6 & 1.6 & 0.0 & 13.0 \\
\hline $13.2 \mathrm{~mm}$ & 0.8 & 0.9 & 0.1 & 6.5 \\
\hline $9.5 \mathrm{~mm}$ & 1.8 & 1.1 & 0.6 & 5.9 \\
\hline $6.7 \mathrm{~mm}$ & 15.9 & 12.2 & 2.0 & 54.0 \\
\hline $4.75 \mathrm{~mm}$ & 22.0 & 7.0 & 5.0 & 38.5 \\
\hline $3.35 \mathrm{~mm}$ & 14.4 & 3.5 & 6.4 & 25.6 \\
\hline $2.36 \mathrm{~mm}$ & 13.9 & 4.7 & 4.9 & 28.3 \\
\hline $1.18 \mathrm{~mm}$ & 17.2 & 7.7 & 3.9 & 33.2 \\
\hline $0.6 \mathrm{~mm}$ & 8.5 & 3.3 & 2.0 & 15.0 \\
\hline Pan & 5.0 & 1.8 & 1.5 & 11.5 \\
\hline \multicolumn{5}{|l|}{ Starch particle size } \\
\hline Geometric mean particle size, $\mu \mathrm{m}$ & 3,349 & 857 & 1,836 & 5,619 \\
\hline Starch particles/g & 1,065 & 1,536 & 25 & 11,908 \\
\hline Surface area, $\mathrm{cm}^{2} / \mathrm{g}$ & 18.3 & 3.6 & 9.5 & 25.6 \\
\hline $\mathrm{KPS}^{1} \%$ of starch $<4.75 \mathrm{~mm}$ & 58.9 & 15.8 & 24.5 & 89.7 \\
\hline
\end{tabular}

${ }^{1} \mathrm{KPS}=$ kernel processing score (Ferreira and Mertens, 2005).

screens of the vertical shaker also present. As an addendum to the principal objective of the experiment, GMPS and KPS of starch within corn silage are highly related and effectually measure the same thing. The relationship between GMPS and KPS is presented in Figure 1 , and GMPS can be estimated from KPS using the following equation: GMPS, $\mu \mathrm{m}=7,491+(-93.81 \mathrm{KPS}$ $\left.+0.37 \mathrm{KPS}^{2}\right),\left(\mathrm{R}^{2}=0.96\right)$, where KPS $=$ percentage of starch $<4.75 \mathrm{~mm}$. This addendum is added as an aid to laboratories who wish to convert GMPS and KPS units.

Calibration and cross-validation statistics for NIRS analysis of starch, GMPS, SP, SSA, and KPS of starch in corn silage are presented in Table 2. Calibrations developed from the negative control spectra (1-mm grind) were effective $\left(R^{2}=0.99\right)$ for predicting starch content of corn silages, but NIRS calibrations to predict GMPS, SP, SSA, or KPS of corn silage were unattainable. Starch is a chemical component well predicted by NIRS (Mentink et al., 2006), but, as expected, grinding through a 1-mm screen mitigated differences in original GMPS, SP, SSA, and KPS in corn silages, making NIRS prediction of SP size characteristics in corn silage infeasible. The primary reason why negative control spectra were evaluated was to evaluate whether any chemical artifacts in corn silage with NIRS absorption regions were related to SP size characteristics in whole undried, unground corn silage. Results suggest that there were no NIRS absorption regions in $1 \mathrm{~mm}$ of ground corn silage that were correlated with SP size characteristics in whole corn silage. Consequently, attainable NIRS predictions for SP size characteristics in corn silage using a natural product cell should be related primarily to NIRS absorption regions associated with characteristics of the particle size of starch and not artifact chemical constituents.

The utility of NIRS to predict starch, GMPS, SP, SSA, and KPS of corn silage using spectra derived from whole undried, unground corn silage scanned via a natural product cell also are presented in Table 2. All NIRS calibrations attempted had low $\mathrm{R}^{2}$ and high standard error of cross validation, indicating that NIRS calibrations had limited value (Sinnaeve et al., 1994). The reason for failure of NIRS to predict SP size characteristics in whole undried, unground corn silage may be related to interference of long forage particles and cobs associated with corn silage that were included in the natural product cell when scanned. In contrast, when spectra were obtained from undried, unground corn silage that passed through a $19-\mathrm{mm}$ screen before scanning, NIRS calibrations for GMPS, SSA, and KPS in corn silage were improved markedly (Table 2 ). Calibrations for SP were, however, still unattainable $\left(\mathrm{R}^{2}=\right.$ 0.51). Spectra obtained from corn silage that passed through a $19-\mathrm{mm}$ screen before scanning predicted GMPS, with an $R^{2}=0.85$ and SE of calibration $=299$ $\mu \mathrm{m}$. Cross validation revealed some loss in performance of NIRS equations $\left(R^{2}=0.76\right)$ for GMPS, but results indicate that standardizing total particle size of undried, unground corn silage before scanning in a natural product cell may yield a viable NIRS method to predict SP size characteristics within corn silage. Attempts to optimize these techniques with larger sample databases and other prescanning separation techniques are warranted. 


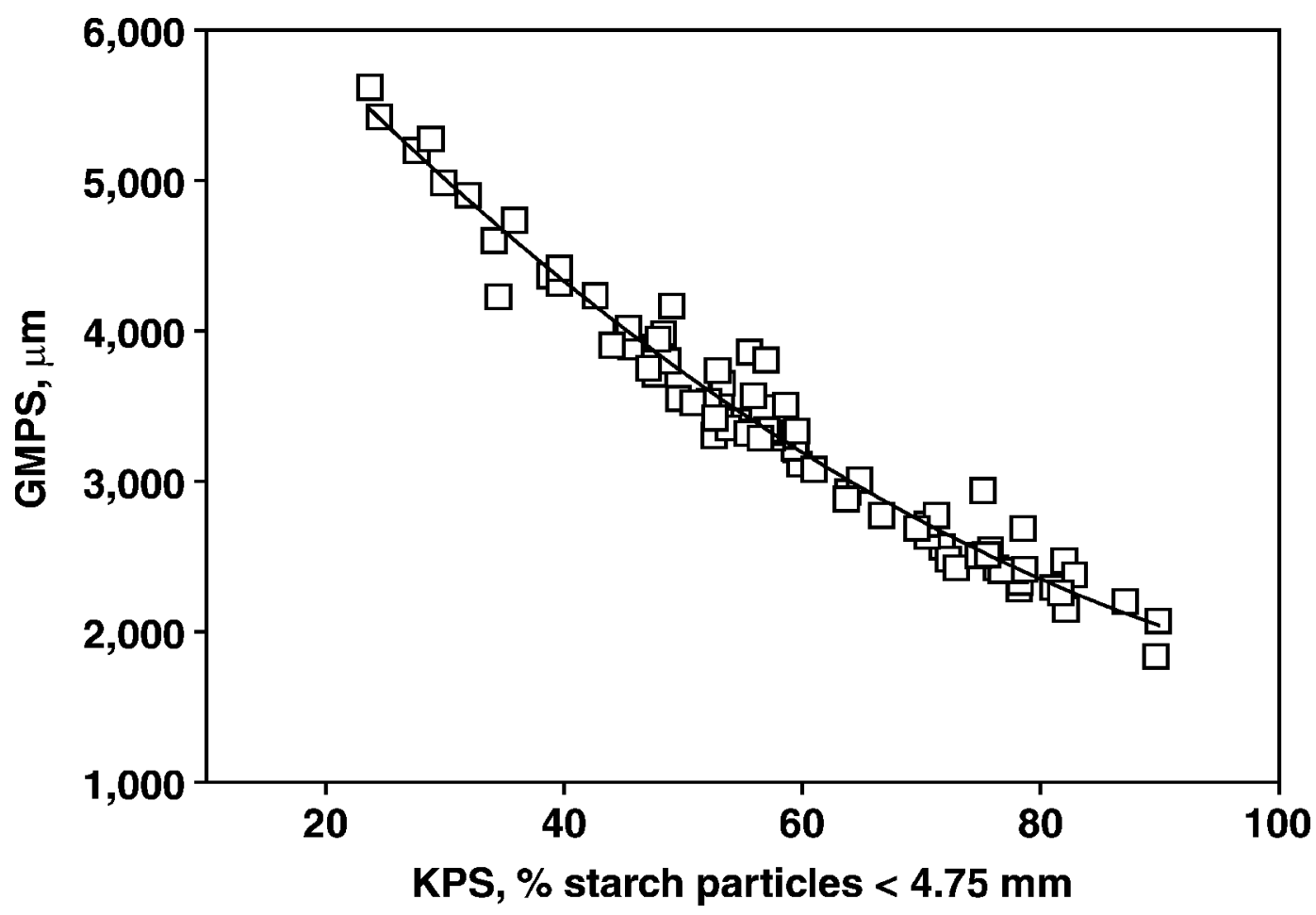

Figure 1. The relationship between kernel processing score (KPS, \% of total starch $<4.75 \mathrm{~mm}$ ) and geometric mean particle size (GMPS, $\mu \mathrm{m})$ of starch within corn silage $\left(\mathrm{R}^{2}=0.96\right)$, where GMPS, $\mu \mathrm{m}=7,491+\left(-93.81 \mathrm{KPS}+0.37 \mathrm{KPS}^{2}\right)$.

Table 2. Calibration and cross-validation statistics for near-infrared reflectance spectroscopy analysis of starch

\begin{tabular}{|c|c|c|c|c|c|c|}
\hline \multirow[b]{2}{*}{ Nutrient } & \multicolumn{4}{|c|}{ Calibration $^{1}$} & \multicolumn{2}{|c|}{ Cross validation $^{2}$} \\
\hline & Transformation & T outliers & $\mathrm{R}^{2}$ & SEC & $\mathrm{R}^{2}$ & SECV \\
\hline \multicolumn{7}{|l|}{ Dried ground corn silage, $1 \mathrm{~mm}$} \\
\hline Starch, \% of DM & $1,2,2,1$ & 1 & 0.99 & 0.8 & 0.98 & 1.1 \\
\hline Geometric mean particle size, $\mu \mathrm{m}$ & $2,10,10,1$ & 2 & 0.45 & 569 & 0.37 & 615 \\
\hline Starch particles/g & $1,10,10,1$ & 4 & 0.26 & 614 & 0.23 & 624 \\
\hline Surface area, $\mathrm{cm}^{2} / \mathrm{g}$ & $1,4,4,1$ & 2 & 0.45 & 2.5 & 0.34 & 2.7 \\
\hline $\mathrm{KPS},{ }^{3} \%$ of starch $<4.75 \mathrm{~mm}$ & $2,10,10,1$ & 3 & 0.29 & 12.6 & 0.21 & 13.4 \\
\hline \multicolumn{7}{|l|}{ Undried, unground corn silage } \\
\hline Starch, \% of DM & $1,5,5,1$ & 5 & 0.65 & 4.2 & 0.51 & 5.0 \\
\hline Geometric mean particle size, $\mu \mathrm{m}$ & $2,10,10,1$ & 4 & 0.32 & 644 & 0.27 & 678 \\
\hline Starch particles/g & $2,10,10,1$ & 5 & 0.13 & 589 & 0.13 & 594 \\
\hline Surface area, $\mathrm{cm}^{2} / \mathrm{g}$ & $2,10,10,1$ & 5 & 0.31 & 2.8 & 0.20 & 3.1 \\
\hline $\mathrm{KPS}, \%$ of starch $<4.75 \mathrm{~mm}$ & $2,2,2,1$ & 2 & 0.38 & 12.0 & 0.22 & 13.5 \\
\hline \multicolumn{7}{|c|}{ Undried, unground corn silage, separated ${ }^{4}$} \\
\hline Starch, \% of DM & $2,5,5,1$ & 2 & 0.79 & 3.2 & 0.64 & 4.2 \\
\hline Geometric mean particle size, $\mu \mathrm{m}$ & $2,10,10,1$ & 3 & 0.85 & 299 & 0.76 & 400 \\
\hline Starch particles/g & $1,10,10,1$ & 2 & 0.51 & 442 & 0.40 & 492 \\
\hline Surface area, $\mathrm{cm}^{2} / \mathrm{g}$ & $2,10,10,1$ & 3 & 0.81 & 1.4 & 0.71 & 1.8 \\
\hline $\mathrm{KPS}, \%$ of starch $<4.75 \mathrm{~mm}$ & $1,7,7,1$ & 0 & 0.81 & 7.0 & 0.68 & 9.0 \\
\hline
\end{tabular}

${ }^{1} \mathrm{SEC}=$ standard error of calibration. Transformation values equal order of derivative function, segment length $(\mathrm{nm})$, segment length $(\mathrm{nm})$ of first smoothing, and segment length $(\mathrm{nm})$ of second smoothing. T outliers $=$ number of samples considered as spectral outliers.

${ }^{2} \mathrm{SECV}=$ standard error of cross validation.

${ }^{3} \mathrm{KPS}=$ kernel processing score (Ferreira and Mertens, 2005).

${ }^{4}$ Near-infrared reflectance spectra obtained from undried, unground corn silage that passed through a 19-mm screen. 


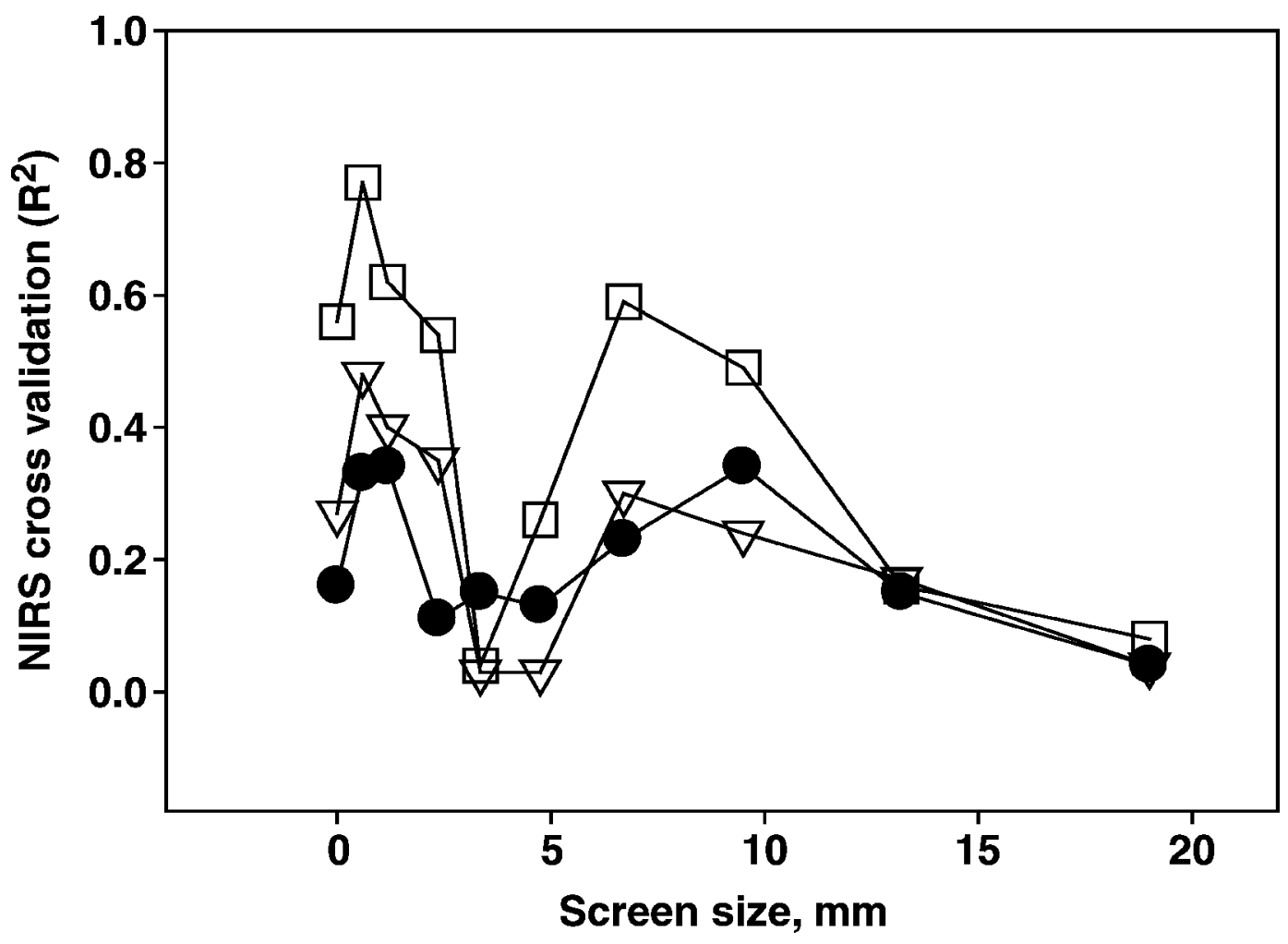

Figure 2. Cross-validation coefficient of determinations of near-infrared reflectance spectroscopy (NIRS) equations to predict corn silage starch particles remaining on vertical shaker screens of various sizes when spectra were obtained from $1 \mathrm{~mm}$ of dried ground corn silage $(\bullet)$, whole undried, unground corn silage scanned using a natural product cell $(\nabla)$, or undried, unground corn silage that passed through a 19-mm screen before scanning with a natural product cell ( $\square$ ).

The principles of improved NIRS prediction of GMPS, SSA, and KPS when whole undried, unground corn silages were separated using a 19-mm screen before scanning are visually presented in Figure 1. Individual NIRS calibrations were developed for starch (\% of starch) retained on each screen of the vertical shaker and pan $(\mathrm{n}=10)$ when NIRS spectra were obtained from 1-mm ground samples; whole undried, unground corn silage; and undried, unground corn silage that passed through a $19-\mathrm{mm}$ screen. Individual NIRS calibrations were made for starch as a percentage of total starch retained on each vertical shaker screen to explore which spectral origin and which SP sizes were best related to NIRS absorption. The $\mathrm{R}^{2}$ of cross validation of NIRS equations are plotted for each spectral origin and starch retained on each screen of the vertical shaker (Figure 2). When spectra were obtained from $1 \mathrm{~mm}$ of ground corn silage or whole undried, unground corn silage using a natural product cell, NIRS prediction of starch retained on any individual screen of the vertical shaker was low $\left(R^{2}<0.40\right)$, suggesting spectra obtained from $1 \mathrm{~mm}$ of ground corn silage or whole undried, unground corn silage via a natural product cell are not conducive to predicting SP size characteristics of corn silage. However, when spectra were obtained from undried, unground corn silage passing through a $19-\mathrm{mm}$ screen before scanning via a natural product cell, the $\mathrm{R}^{2}$ of cross validation improved substantially for starch retained on 9.5, 6.7, 2.36, 1.18, and $0.6 \mathrm{~mm}$ screens and pan of the vertical shaker. Starch particles retained on 9.5- or $6.7-\mathrm{mm}$ vertical shaker screens were predominately whole corn kernels, and starch retained on the 2.36-, 1.18-, and 0.6-mm screens and pan of the vertical shaker are highly processed SP (Ferreira and Mertens, 2005). Regardless of spectral origin, NIRS was challenged to predict corn silage SP retained on 4.75- or $3.35-\mathrm{mm}$ vertical shaker screens. Because starch retained on 4.75 - or $3.35-\mathrm{mm}$ screens of the vertical shaker is predominantly $1 / 4$ kernels of corn (Ferreira and Mertens, 2005), NIRS may have had difficulty distinguishing these particles due to their orientation proximal to the quartz window of the natural product cell. Starch particles could be oriented with the pericarp proximal or the endosperm/germ proximal to the quartz window, which may yield different NIRS absorption regions. We cannot reject or confirm this hypothesis, but data suggest potential inefficiencies in NIRS pre- 
dicting SP that are approximately 4.75 to $3.35 \mathrm{~mm}$ in size.

In conclusion, using spectra obtained from $1 \mathrm{~mm}$ of dried ground corn silage or whole undried, unground corn silage using a natural product cell, NIRS was unable to predict the GMPS, SP, SSA, or KPS of corn silage. In contrast, NIRS prediction potential for GMPS, SSA, and KPS was improved when spectra were obtained from undried, unground corn silage that passed through a $19-\mathrm{mm}$ screen before scanning via a natural product cell. Utilizing the $19-\mathrm{mm}$ screen of the Penn State Forage Particle Separator to remove long forage particles and cobs before scanning undried, unground corn silage in a NIRS fit with a natural product cell maybe a rapid and efficient NIRS method to estimate SP size characteristics in corn silage.

\section{ACKNOWLEDGMENTS}

This project was financially supported in part by a gift from Pioneer Hi-Bred International Inc (Johnston, IA). We would like to thank Bill Mahanna and Fred Owens (Pioneer Hi-Bred International Inc.) for their contributions and support of unrestricted academic research.

\section{REFERENCES}

AOAC. 1990. Official Methods of Analysis. 15th ed. Assoc. Off. Anal. Chem., Arlington, VA

ASAE. 1993. S319.2. Method of determining and expressing fineness of feed materials by sieving. Am. Soc. Agric. Eng., St. Joseph, MI.
Baker, S., and T. Herrman. 2002. MF-2051. Evaluating particle size. Kansas State Univ. Agric. Exp. Stn. Coop. Ext. Serv., Manhat$\tan , \mathrm{KS}$.

Bal, M. A., R. D. Shaver, A. G. Jirovec, K. J. Shinners, and J. G. Coors. 2000. Crop processing and chop length of corn silage: Effects on intake, digestion, and milk production by dairy cows. J. Dairy Sci. 83:1264-1273.

Cooke, K. M., and J. K. Bernard. 2005. Effect of length of cut and kernel processing on use of corn silage by lactating dairy cows. J. Dairy Sci. 88:310-316.

Ehrman, T. 1996. Determination of starch in biomass samples by chemical solubilization and enzymatic digestion. LAP-016. US. Dept. Energy. Natl. Bioenergy Cent., Washington, DC.

Ferreira, G., and D. R. Mertens. 2005. Chemical and physical characteristics of corn silages and their effects on in vitro disappearance. J. Dairy Sci. 88:4414-4425.

Lammers, B. P., D. R. Buckmaster, and A. J. Heinrichs. 1996. A simple method for the analysis of particle sizes of forage and total mixed rations. J. Dairy Sci. 79:922-928.

Marten, G. C., J. C. Halgerson, and J. H. Cherney. 1983. Quality prediction of small grain forages by near infrared reflectance spectroscopy. Crop Sci. 23:94-101.

Mentink, R. L., P. C. Hoffman, and L. M. Bauman. 2006. Utility of near-infrared reflectance spectroscopy to predict nutritional components and in vitro digestibility of total mixed rations. J. Dairy Sci. 89:2320-2326.

Pasikatan, M. C., J. L. Steele, C. K. Spillman, and E. Haque. 2001. Near infrared reflectance spectroscopy for online particle size analysis of powders and ground materials. J. Near Infrared Spectrosc. 9:153-164.

Pérez-Marin, D. C., A. Garrido-Varo, J. E. Guerrero-Ginel, and A. Gomez-Cabrera. 2004. Near-infrared reflectance spectroscopy (NIRS) for the mandatory labeling of compound feedingstuffs: Chemical composition and open-declaration. Anim. Feed Sci. Technol. 116:333-349.

Shenk, J. S., and M. O. Westerhaus. 1991. Population definition, sample selection, and calibration procedures for near infrared reflectance spectroscopy. Crop Sci. 31:469-474.

Sinnaeve, G., P. Dardenne, R. Agneessens, and R. Biston. 1994. The use of near infrared spectroscopy for the analysis of fresh grass silage. J. Near Infrared Spectrosc. 2:79-84. 